\title{
ENTREVISTA \\ ONG Salud sin Límites PERÚ
}

Salud Sin Limites es una ONG formada por profesionales peruanos comprometidos con las comunidades más pobres y vulnerables en su búsqueda por mejorar las condiciones de salud, como un factor clave para su desarrollo integral.

$\mathrm{Su}$ trabajo es apoyado por Health Unlimited (HU), asociación británica con sede en Londres, creada el 30 de mayo de 1984 que, tras observar las necesidades de las zonas más deprimidas de nuestro país, decide empezar a trabajar en el Perú en 1997, específicamente en Ayacucho, uno de los departamentos más pobres del país y el más afectado por la violencia política.

Tras los logros alcanzados y siguiendo con la estrategia de descentralización impulsada por HU, se crea en 21 de mayo de 2002 la ONG Salud Sin Limites Perú, con el objetivo que las personas más pobres y perjudicadas por la violencia y la desigualdad, accedan a los servicios de salud, mejoren su calidad de vida y protejan su bienestar y el de sus familias.

Como institución tiene la visión de ayudar a crear un mundo en el que las comunidades más vulnerables disfruten de su derecho a la salud y el bienestar. Dan prioridad a la población indigena y a las comunidades afectadas por los conflictos y la inestabilidad política.

A partir de enero del 2008 puso en marcha el tema de los Derechos en Salud Sexual y Salud Reproductiva una iniciativa para retomar su accionar con los adolescentes y jóvenes de dos zonas de nuestro país: Huanta y Satipo.

Jorge Yactayo Sánchez

Estudios concluidos de Maestría en la Pontificia Universidad Católica del Perú.

Estudió en la Escuela de Ciencias de la Comunicación de la Universidad Nacional Mayor de San Marcos. Docente de la Universidad Femenina del Sagrado Corazón. 
Conversamos con la psicologa Claudia Lema, Directora Ejecutiva de Salud Sin Limites Perú, para abordar el tema de cómo manejan ellos con las comunidades campesinas y nativas el tema de Comunicación y Cultura en su quehacer diario.

\section{¿Qué tipo de proyectos están trabajando ahora y que estrategia comunicacional tienen para llegar a las personas?}

Los partos con pertinencia cultural en las comunidades amazónicas.

Existen varias estrategias. Con los terapeutas tradicionales o curanderos, para sumarlos al objetivo, la idea no es que ellos dejen de hacer lo que hacen normalmente, sino ponerlos en diálogo con el establecimiento de salud.

El personal nuestro facilita ese diálogo; tenemos ya bastante tiempo trabajando en la parte andina y amazónica y las comunidades en general nos tienen confianza. Más de la que le tienen a los establecimientos de salud, en muchos casos. El personal rota mucho, no se quiere quedar, no se conocen tanto con la población como nosotros que trabajamos allí varios años y además nuestra actitud es más conciliadora.

La gente que va a trabajar a los establecimientos de salud en esta zona no está preparada para lo que va a encontrar y, a veces, quiere cubrir sus indicadores de asistencia al establecimiento a toda costa, o quiere hacer bien su trabajo como le han enseñado que debe hacerlo en una zona urbana mestiza, donde todo el mundo habla el mismo idioma.

La gente de las comunidades no es ignorante y desea estar bien, pero, para ellos, no pasa, necesariamente, por ir al establecimiento de salud.

\section{¿Y el Estado no tiene política de comunicación en el área de salud?}

A veces, la política y las normas no las conoce todo el mundo, o si las conocen no sabe cómo aplicarlas. El problema con la salud es que los proveedores de salud están entrenados de una manera que no incluye tomar conciencia de que las personas son diferentes. 
La posición del profesional de la salud, así como ha sido entrenado, es para decir: "yo soy el profesional, tú no sabes".

\section{¿En cuántas zonas trabajan ahora y con qué comunidades nativas?}

En tres zonas: Huancavelica, Ayacucho y Junín (Satipo). En Satipo, con los ashaninkas y nomatsiguenga.

\section{¿Con quién es más complicado relacionarse con las Comunidades Nativas o Comunidades campesinas?}

Un sello de la Institución es hacer que el trabajo que uno propone a la comunidad presente pertinencia con la cultura y las necesidades que sus mismos miembros hayan identificado en sus diagnósticos comunitarios. Por ello, es difícil que la gente se rehúse. Si ellos identifican que es un problema como se les atiende en un establecimiento de salud, nosotros tratamos de ayudar a que se dialogue y se dé un mejor trato.

Si ellos identifican que los niños tienen mucha diarrea, nosotros podemos proponer que para solucionar este problema, el saneamiento puede ayudar. $Y$ dialogamos sobre varias alternativas, sobre cuál le puede gustar o cuál puede ir de acuerdo con su forma de ver las cosas.

La gente es muy diferente en la zona quechua y la amazónica, por el nivel de organización. En la Selva están muy organizados. En la Sierra, menos.

Para trabajar en la selva, se debe pedir permiso en cada instancia; en cambio, en la sierra, se trabaja con la gente de la comunidad y el alcalde. La gente que trabaja con nosotros es de allí, logra hacerse querer conversando.

\section{¿Qué tipo de conflictos han tenido en su trabajo?}

Delicados y graves, no; conflictos como mal entendidos, sí.

No es el paraíso trabajar en comunidades amazónicas ni en comunidades andinas, pero los temas que tratamos son más o menos de 
consenso. Es decir, la gente en general no va estar en contra de trabajar por la salud de los niños, madres o mejorar el saneamiento.

No son temas controversiales. Si trabajáramos otros temas, podríamos ganarnos enemigos.

\section{¿Y sobre el parto con pertinencia cultural? Cuéntanos cómo identificaron el problema?}

Es uno de los temas que hemos trabajado más. La salud materna es una prioridad nacional desde hace mucho tiempo: que fallezcan las mujeres al dar a luz, ha preocupado mucho a las autoridades.

Cuando se trata de estudiar el porqué la gente muere, se encuentra que una de las razones es porque no va a los establecimientos de salud y, cuando se ve que no van al centro de salud, encuentras porque están lejos, no hay dinero para el pasaje, pero también hay un fuerte componente en que la atención que reciben no es como ellos les gusta.

Investigando por ese lado, se encuentra que se percibe maltrato y no hacen las cosas como a ti te gustaría que te las hagan. Eso que a uno le ponen en una camilla ginecológica, solita con una batita delgada y que le hacen todo lo que le hacen a uno. No le gusta a nadie.

La gente de las comunidades con que trabajamos percibe que muchas de esas cosas le hacen daño; por ejemplo, el instrumental de metal es frío y eso va en contra del proceso de parto. No te dejan tomar lo que tu quieres tomar y eso te hace dańo y pone en peligro a tu bebe. No solamente que no es agradable sino que van en contra de tu salud y la del bebé.

Partiendo de que existía este tipo de problemas, se ha trabajado en investigaciones sobre cómo es el parto en la comunidad, que referencias tienen las personas de la comunidad y se ha propiciado un proceso de diálogo entre los servicios de salud y la comunidad, para ver qué es negociable qué cosa se puede incorporar; también, si es que la ciencia occidental ha probado que hay algunas cosas que son dañinas. Se busca un proceso de negociar con argumentos y no obligando a la gente a que se corte el cordón umbilical con algo que no haya sido esterilizado.

Es investigar, dialogar y modificar. 


\section{¿Qué herramientas comunicacionales usan para capacitar a las comunidades?}

Hacemos talleres y capacitaciones. También realizamos radionovelas, ferias de salud, teatro popular, títeres, concurso de canto y dibujo. Pasantías, visitas a otras comunidades donde las cosas funcionan bien, demostraciones prácticas de las cosas que estamos constatando que funcionan.

El campo no es tan amigo de las letras; no tiene tanta exposición a material escrito. Por ello, los talleres se realizan empleando la menor cantidad de letras.

Un punto muy importante para nosotros es detectar qué cosas conocen; muchas veces, ellos saben casi todo lo que es necesario, solo que de manera diferente; falta organizarse para que se practique o que los demás reconozcan que es muy valioso el aporte.

\section{Cuéntanos sobre cómo la gente participa en los programas de radio y los sociodramas.}

La radio es una herramienta muy importante en nuestro trabajo. No solamente para transmitir los conocimientos sobre salud sino también porque permite que los promotores de salud sean los locutores y que la gente de la comunidad participe: crean sus programas y guiones, hacen las encuestas a la comunidad y realizan sus radiogramas. Todo esto les ha dado muchas herramientas de expresión y seguridad. El hecho de que su programa se escuche en toda la provincia y que su primo que vive a cinco horas le reconozca la voz y la gente los saluden en las calles, les ayuda mucho a mejorar la autoestima.

Correo electrónico: joryactayo@gmail.com 
